\title{
Agricultural Development NGOs, Anthropology, and the Encounter with Cultural Knowledge
}

\section{Chris J. Shepherd}

Chris J. Shepherd is a researcher at the Globalism Institute, a social science research center within the School of International Community Studies, RMIT University, Melbourne, Australia.

\begin{abstract}
This article is intended to contribute to development anthropologists' understanding of the role of cultural knowledge in the context of agricultural rural development projects run by NGOs in the Third World. Paying particular attention to narrative constructs of deficiency in local livelihoods and knowledge of indigenous peasants of highland Peru, it is argued that these constructs impede a fuller appreciation of the value of culture and the potential of local knowledge for development and conservation. In this respect, the role of development anthropologists is crucial, not only because of their familiarity with cultural knowledge but also because they are positioned to harmonize developmentalist agendas with cultural knowledge. Drawing on ethnographic data, the article examines one particular case of a Peruvian NGO seeking to incorporate indigenous knowledge into its praxis. The tensions that emerge through this incorporation are investigated vis-à-vis the explanatory frameworks and agendas of conventional agricultural development models. It is concluded that the use of local knowledge in agricultural development necessarily entails a shift away from positivist understandings of knowledge, and that the task of development anthropologists may involve challenging some of the deep assumptions that development embodies. [Keywords: agricultural development, indigenous knowledge, NGOs, development anthropology]
\end{abstract}

\section{Introduction}

Among the practices of "alternative development" for rural people of the Third World, it is now considered important that nongovernmental devel- opment organizations (NGOs) understand and value the local culture and knowledge of target populations. Indeed, it is now the case that Northern donors often insist that their Southern counterparts devise projects "compatible" with local culture. The resources available to NGOs wishing to deepen their understanding of the cultures of the people they seek to develop are substantially greater than they used to be, particularly with the wide dissemination of anthropological ideas, the proliferation of anthropologists and other social scientists in development careers, and the influx of works documenting and strategizing the usefulness of indigenous or folk knowledge for development and conservation (Altieri 1995; Anderson 1990; Boulding 1989; Browder 1989; Warren 1996a, 1996b; Van Cooten 2001). Yet despite the best intentions of donors and NGOs, cultural knowledge frequently lacks relevance and applicability to the planning and operationalization of projects, and for their part, development anthropologists can be frustrated in their attempts to draw development staff out of their received notions of what development means with its characteristic emphasis on modern technology transfer and attendant notions of efficiency and progress.

The tendency to overlook cultural or local knowledge is due to the persistence of common assumptions that pervade agricultural development and comprise its interventionist ethos. In particular, development expertise lays claims to an objective view of the problems of target populations, which serves to legitimize the developmentalist agenda while underrating the potential contributions of local knowledge. This promotes a skewed situation where in many development projects worldwide, NGOs provide the "technical assistance" while locals provide the labor. Development workers point to local or "traditional" knowledge as part and parcel of the problem of low productivity, gender inequality, poverty, etcetera, in the expectation that these adversities will be alleviated given the right technology and expertise (Shepherd 2004). This not

Culture and Agriculture, Vol. 27, No. 1, pp. 35-44. ISSN 1048-4876. (C) 2005 by the American Anthropological Association. All rights reserved. Please direct all requests for permissions to photocopy or reproduce article content through the University of California Press's Rights and Permissions website, www.ucpress.edu/journals/rights.htm. 
only encourages an ignorance of local knowledge (Hobart 1993) but also reinforces a prevalent attitude that development experts understand the problems of target populations in an objective fashion while the latter fail to see themselves as they "really are" and lack the capacity and know-how to exit the cycle of poverty in which they are immersed.

Within this context of asymmetrical knowledge relations, attempts to meaningfully incorporate local knowledge tend to be weak. In this article I argue that NGOs cannot succeed in utilizing local knowledge without challenging some of the fundamental tenets of development, not only in terms of development's reliance on external or foreign technologies but also in terms of the kinds of narratives that are invoked to define the problematic of the local environment. To illustrate these ideas, I draw on fieldwork carried out in the southern Peruvian Andes in 1997 and 1998, focusing on the experience of one NGO and the connections it forged between gender, locally held knowledge, agricultural production, and environmental sustainability. Without the dissemination of anthropological views of knowledge and culture, and indeed without the direct influence of a group of actors who understood knowledge and culture to be intimately related, these changes to the NGO's practices would never have been realized.

\section{Knowledge as Culture and the Culture of Agriculture}

Ever since the "functionalist turn" in anthropology, local knowledge and technology have played a prominent if analytically varied role in discussions of culture. With the mid-century arrival of the ethnoscientific tradition in particular, the limits of relativism were stretched by a methodology that proposed that the cultural knowledge of anthropology's subjects was knowable on its own terms, promising to uncover a people's cognitive system and their subjective explanation of the world. In the rural agricultural context in particular, it has been demonstrated that local knowledge is not simply an isolated matter of possessing a cognitive capacity to achieve a given task. Rather, it is intrinsically related to the broader gamut of social relations and relations with nature. In farming communities, local knowledge has as much to do with the division of land and labor, sociopolitical formations, and worldview as it does with the technical aspects of tillage, sowing, and harvesting. Indeed, in the Andes as elsewhere, technical knowledge and cosmology are intimately related (Apffel-Marglin 1998; Ploeg 1993).

One of the most important contributions of anthropology has been not only to reveal the actual content of local knowledge but also to provide a counterbalance to the scientific universalism of modern discourses on the Third World (Escobar 1995) and to guard against the temptation, prevalent in ethnoscience itself, to pit local knowledge against Western scientific knowledge under the asymmetrical assumption that the latter offers the objective measure useful for assessing the "accuracy" of all other knowledge systems (Turnbull 2000; Verran and Turnbull 1995). As such, Western epistemology stands out as the only system to have established a notion of "objective" knowledge in the form of modern science (Latour 1993).

These theoretical advances in comparative anthropology are important for the way we understand the "cross-cultural encounter" in any Third World context. In the Peruvian highlands, an autochthonous or Andean knowledge system intersects with a Western knowledge system now operationalized as much through development as through the "natural" diffusion of knowledge and artifacts. Notwithstanding the new postcolonial critiques of pure and territorially demarcated cultures or forms of knowledge (Gupta and Ferguson 1997), Andean ethnographic studies continue to locate a distinctly Andean stock of knowledge, technology, and cultural practices (Gelles 2000). Murra (1972), Golte (1980), and Morlon et al. (1992), among others, have shown how agriculture in the topographical verticality of the Andes has been, and remains, intimately tied up with political control, communal organization, crop diversity, and risk management. In various ways, these authors have emphasized the nexus between aspects of knowledge and culture. Other researchers, notably Apffel-Marglin (1994, 1998), have gone further to examine the role of knowledge in its comprehensive ontological domain, thereby questioning the philosophical split between epistemology and ontology and, concomitantly, the divide between nature and society (Latour 1993).

Yet the narratives we routinely encounter in the Andean development world continue to reveal an "inefficient" and "inadequate" indigenous technological capacity in the Andes. In order to construe indigenous knowledge in such deficient terms, development has historically dismissed the relativism of knowledge in the production of an overarching development discourse according to which Andean agriculture could 
be assessed on supposedly technical grounds to determine its levels of productive output and efficiency. Despite the visage of neutrality, the fact that Andean knowledge has "measured-up" unfavorably has been built into the very criteria by which different efficiencies have been compared (Verran and Turnbull 1995). Another stream of anthropological studies has documented the effects of this asymmetry in the everyday practices of development, which, it has been argued, have accelerated the erosion of local knowledge (Hobart 1993; Grillo and Stirrat 1997). Some critics have extended this epistemological prejudice to an analysis of the social relations and power dynamics that prevail between development workers and target populations in arguing that the marginalization-or "invisibility" —of local people and local knowledge are one and the same under the auspices of an authoritative development praxis (Ploeg 1993; Wynne 1996).

As in many parts of the rural Third World, agricultural development in the Andes has been of equivocal value. In Peru, development programs have enabled the state and coastal mestizos to increase their control over Andean highlanders to expedite the assimilation of the peasant economy into the national economy (Gelles 2000; Shepherd 2004). While the success of these programs has been questionable in terms of economic returns to beneficiaries, particularly to women (Mayer and Glave 1992), the ecological impacts have been indubitably adverse. In particular, the sustained attempts to bring intensive agricultural practices to highlanders by way of hybrid seeds and their attendant inputs have occasioned a rapid diminution of genetic diversity in the Andes as elsewhere in the world (Dueñas et al. 1992; Shiva 1991). Whereas environmental degradation is now generally cited as a primary cause of underdevelopment and poverty (for which the solution is "sustainable development"), it is rarely acknowledged that development has contributed enormously both to loss of biodiversity and to the loss of cultural knowledge (Apffel-Marglin 1998). Indeed, biodiversity in the Andes is intimately connected to the agricultural practices and knowledge of the indigenous farmers of the Andes. As the following case study of one NGO reveals, looking for new ways of drawing on local knowledge for development and conservation has far-reaching implications for how knowledge is understood and framed by anthropologists and practitioners of development alike.

\section{The Culture of Biodiversity}

Alongside hundreds of other agricultural development NGOs, Centro de Servicios Agropecuarios (Center for Agricultural and Livestock Services-henceforth CESA) was established in 1984 for the peasant communities of Abancay and soon moved its operations from there to Paucartambo with its headquarters in Cusco. Conventional development models, in particular Integrated Rural Development and Community Development (see Figure 1), were followed for several years until a reevaluation of CESA's activities revealed that agricultural projects based on the introduction of high-yielding seed, irrigation technology, and inputs were falling short of expectations. In 1994, a new program called "The Culture of Biodiversity" was inaugurated under the guidance of another NGO, based in Lima, which strongly criticized standard development models while promoting alternatives that affirmed campesino culture and agriculture.

The objective of that program was the conservation and extension of genetic diversity within communal spaces in Cusco's northeastern province of Paucartambo. The impressively high density of diversity in plants in this region has been typically attributed to its geographical location on the fringe between the Andean highlands and the Amazonian lowlands and to the preponderance of multiple ecological niches. Thus geographical and climatic determinants have tended to organize knowledge of biodiversity in scien-

\section{Figure 1}

Monoculture: a crop of a high-yielding potato variety

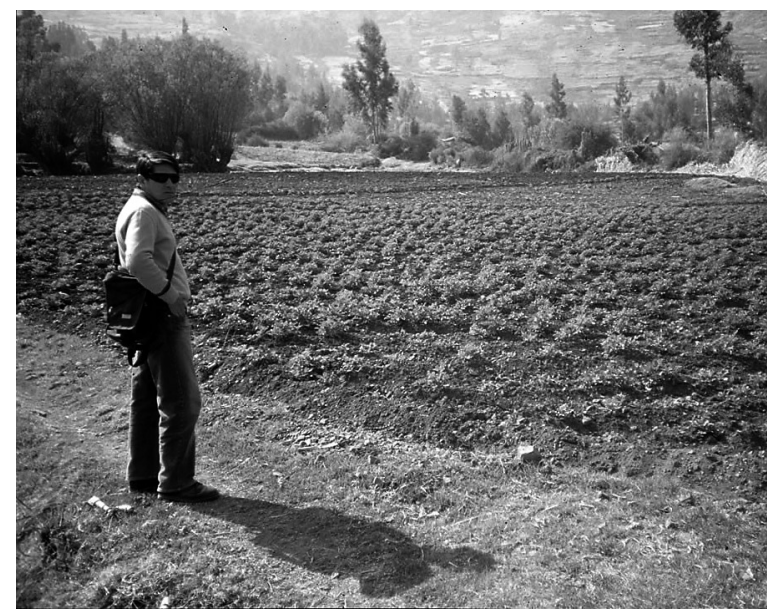


tific terms, thereby underrating the import of local people in this process (see Zimmerer 1996). In contrast to this view, CESA began to treat biodiversity as a cultural phenomenon, acknowledging the role of peasants as a fundamental part of the regeneration of that diversity. CESA proposed that diversity was closely connected with, even indistinguishable from, peasants' agricultural and communal practices and rituals and with their ongoing communications with each other and with the Pachamama, the Mother Earth. It emphasized the centrality of the vigorization of strategies proper to peasant experience and defined its relationship with the peasant communities as one of "accompaniment." CESA accompanied communities in their recourse to their own knowledge, technologies, and cultural traditions to conserve diversity as well as to maintain or increase production. Accompaniment reimagined what development was about. It underpinned, firstly, the view that indigenous knowledge was an innate potential rather than a deficiency justifying an interventionist ethos and urging replacement technologies. Secondly, accompaniment informed a nonhierarchical knowledge relationship between extension workers and campesinos such that the former no longer framed themselves as those who delivered expert advice, know-how, and new technologies to "inexpert others."

CESA understood the intrinsic importance of Andean knowledge to agro-diversity in two primary ways: the distribution of seed and the nurturing of the chacras - the cultivated plots of land (see Figure 2). Distribution was not the contractual and commercially regulated mode of distribution that transpires in Western economic life. Rather, it was governed by informal and flexible networks that exist between families and communities-the ayllu-according to relations of reciprocity. Peasants described distribution in terms of seed paths-los caminos de las semillas. In so speaking, they treated seed not as inert cargo transported by humans, but imputed a measure of agency to seed itself, as if that seed were alive and self-motivated. This is indeed the case within the Andean worldview, where all entities from rocks, rivers, trees, and seed are imbued with life (Allen 1988; Apffel-Marglin 1998).

The first part of CESA's engagement with local knowledge was descriptive. CESA mapped the caminos of the seeds by learning from campesinos in which communities which type of seed was circulated. Each community revealed a distinct seed distribution "map," which was conveyed through oral communication. The maps of peasants were marked by a combination of
Figure 2

A farmer tends to his chacra. Note the many chacras in
the background.

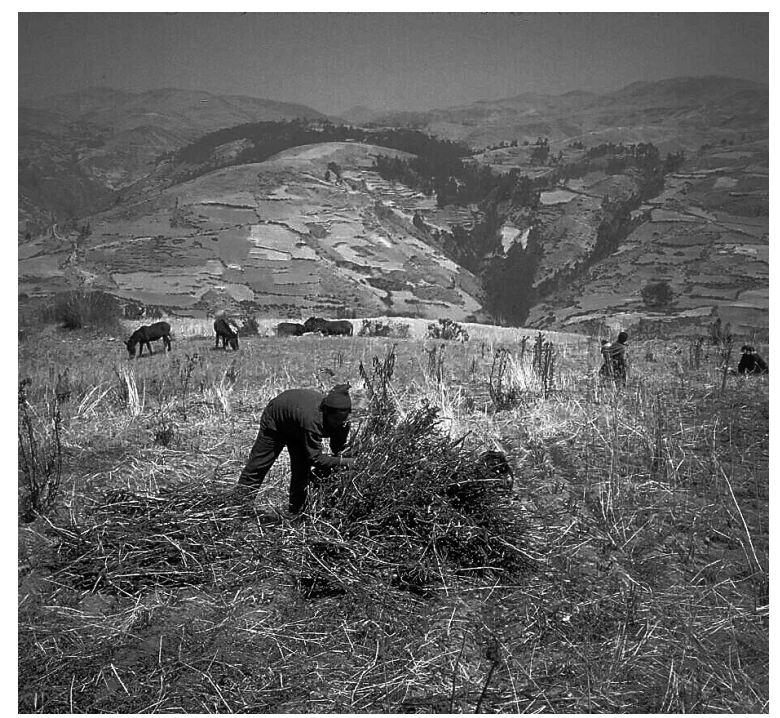

their knowledge of the phenotypic traits of various seed as well as by the physical action, experience, and memory of carrying seed from one place to the next (see Rengifo and Ishizawa 1997). CESA's maps were documented translations thereof, interrelating standard geographical representations of physical space with peasant "maps." The aim was not to specify or quantify spatial requirements (and so the maps appeared as sketches) but rather to determine how and where seeds came and went. Mapping seed paths required that CESA find out what range of seeds were available in any given community or region. CESA made counts of different varieties and identified them according to the local taxonomy in Quechua, ordering the data into charts. Accordingly, agro-diversity became known to CESA as an approximation of agro-diversity as it was experienced by the campesinos (see Figure 3).

Maps and charts were derived from peasant testimony, which characteristically linked knowledge of seed circulation with other aspects of cultural knowledge. Translated from the Quechua, the following testimony of Don Quintin Quispe of Sipascancha Alta appeared in CESA's annual report:

The potato seed movement takes place at three levels. Firstly, the seed moves internally and between families from one plot to another. This continues to 


\section{Figure 3}

A display of the diversity of seed from one area

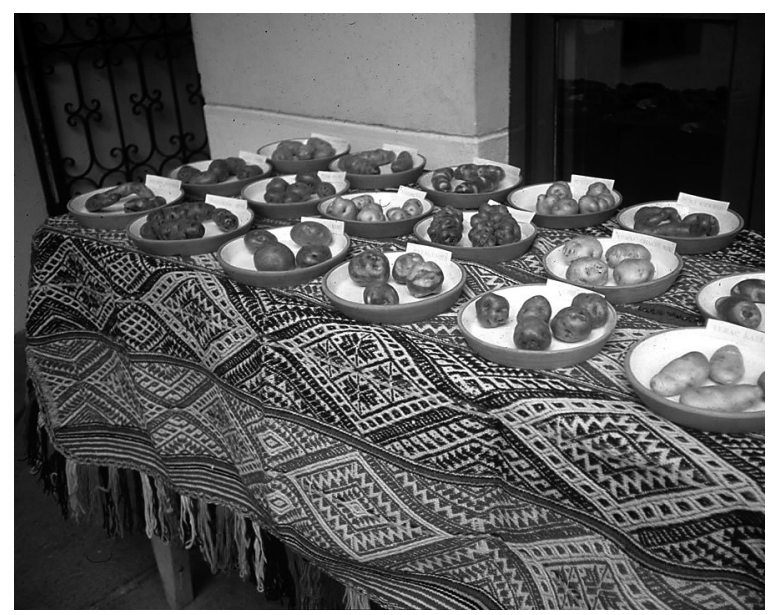

be practised by sale, by exchange and by ayni. ${ }^{1}$ Secondly, seed moves from the loma (high altitudes) to the $q^{\prime}$ ata (lower altitudes) ${ }^{2}$ and vice versa in order to 'refresh' 3 the seed-the preferred seed should be sown under chukit so that the harvest is clean and healthy. Thirdly, seed moves between communities, especially when the season is not so favorable in our community so we need to resort to neighboring communities like Chahuaitiri and Colquepata and to the Cusco market where we look for seeds that have come from Chincheros and Urcos.

The report went on to list the 51 varieties of potato in Sipascancha Alta. It identified the community as a locus of genetic agricultural diversity and maintained that the informal seed exchange practices by peasants were critical aspects to maintaining and enhancing agro-diversity and well-being.

In all, some 250 varieties of potato-one-third of the estimated total-in the province of Paucartambo were known to CESA at the time of research. Diversity was concentrated in the higher regions of Paucartambo, and numerous varieties were restricted to specific ecological niches. It appeared that some varieties were few in number and extension, a phenomenon that CESA attributed to the disproportionate degree to which hybrid seed had been promoted and to imbalances brought about by commercialization.

The second dimension to CESA's accompaniment was proactive. It was concerned with recuperating na- tive varieties of potato as well as other cultivars and medicinal plants to communities and families where they were now inexistent. The lack in diversity in a community was not seen to result from an absence in technology or know-how but rather from a reduction in the local practices of seed exchange. Thus CESA encouraged peasants to exchange seed and plants along routes so that a distribution favorable to diversity was foreseeable (see Figure 4). Ultimately, the goal was not to create the reliance of peasants on the organization as a distributor of seed and plants but to support peasants in taking responsibility for their own distributions.

CESA understood its task as going beyond the facilitation of seed distribution. Seed and diversity were construed not in reductionist terms but in terms of the totality of peasant experience. The following excerpt expresses how "technical," agroecological, and socioreligious matters were treated not differentially but concurrently.

Seed lives in the chacra. The chacra constitutes home, and it is a space of convergence where seed, the Pacha, and people come together in dialogue. For this reason, the condition of the chacra influences the social relations in the community. And it is in this sense that it is important to dedicate time and effort to the upkeep of the chacra: we take care

\section{Figure 4 \\ A CESA employee is impressed by this farmer's potato varieties}

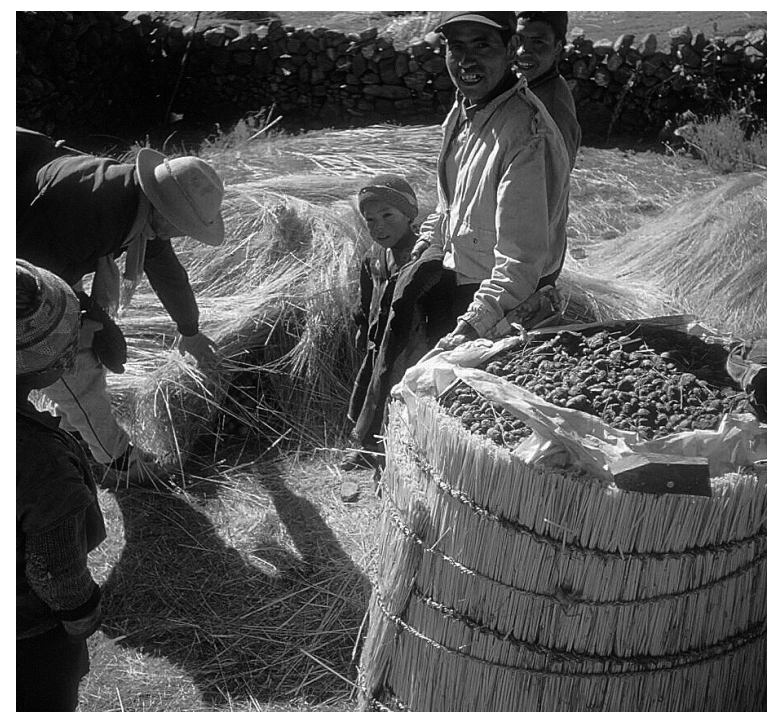


that her fertility does not diminish, that she receives the water that she needs at the right moment, and we watch that communication with the Apus is not interrupted. [Revilla, 1997:8]

Although the success of CESA's accompaniment was judged on diversity counts, "the culture of biodiversity" aimed to embrace the broader context of peasant life, building on practices that were inherently knowable for local people within the parameters of local knowledge, local technology, and existing social relations.

Campesinos taught CESA not only about seed paths, local taxonomy, and landraces. In addition, CESA learned of peasant knowledge of agroecological levels, crop rotation and intercropping, tillage and harvest practices, seed and food storage, food processing, climate prediction, agricultural tools, and the communally organized dimensions of agriculture (Pérez Baca 1996). When workshops took place in Paucartambo, these were not "training courses" that instructed peasants in new technologies and productive techniques. Rather, they were generally directed toward collecting, transcribing, and translating Quechua testimony such that CESA could immerse itself in local ways and perceptions of the world, in view of which the organization devised its accompaniment strategies.

With time, CESA also came to understand gender and its relationship to knowledge differently from how it was conceived within the mainstream of development. Whereas development organizations customarily perceived the duties of women to be congregated in the domestic sphere with limited and subservient engagement in the broader productive processes, CESA found female gender roles to be complementary to those of men, especially in what concerned conservation of genetic resources. The stability and sustainability of ecosystems, livestock, and cultivars depended on the practices and knowledge of local women. Moreover, women possessed specialized knowledge of cultivars and crops and had historically played a critical role in the transmission of knowledge over generations. Rather than stereotyping women as victims (or perpetrators) of environmental degradation, women proved to hold valuable and broad knowledge that attenuated the severity of that degradation. Concomitantly, women's labor was executed in light of that knowledge with rather than under the menfolk. During the entire process of agricultural production including tillage, tending, harvesting, food processing, and exchange, women were involved in important ways, and in many instances (for example, in agricultural ritual and ceremony) their contributions of cognitive and physical labor were central. Rather than assume that women were subordinate and held no valuable knowledge, CESA looked carefully at the complementary roles of women and men in the productive cycle.

Whereas development typically justifies its interventions on the basis of a deficient (inefficient, unproductive, traditional, gender differentiated) Andean agriculture, and more recently, a degrading environment, CESA manifested the curious position of establishing its role in seed distribution vis-à-vis a problematic of conventional intervention:

For various reasons, among which can be mentioned the strong impact of external organizations, the fluidity in the trajectories and exchange of seed has diminished. Consequently, it is necessary to direct efforts at revitalizing this practice. [Revilla, 1997:7]

If "external organizations" are properly understood as development organizations, CESA worked to counter the impact that hybrid seed programs and agricultural modernization have had on biodiversity and indigenous practices, including the complementary relations of knowledge and labor that sustained that diversity.

\section{Discussion}

From a developmentalist standpoint, CESA was likely to be exacerbating the very causes of poverty and underdevelopment rather than alleviating them. Asked about the impact of CESA on the communities of Paucartambo, an observer from a neighboring NGO said he had failed to see any improvement in Paucartambo's communities over the past decade. Certainly, by development's criterion, an "improvement" or vitalization of traditional farmer knowledge would have remained invisible.

A visiting representative of a Dutch sponsor to CESA saw CESA as being involved in an environmental program (of enhancing biodiversity) and not a development program. This coincided with the rubric under which CESA was assessed externally: CESA's activities acquired their legitimacy (and therefore funding) through their appeal to environmental concerns. Understandably, CESA's indigenous knowledge orientation arose at a time when considerable funds became 
available for proposals framed within "sustainable development" and, in particular, the conservation of biogenetic resources. Despite the recent and not unstrained marriage between sustainability and development, CESA pushed for a version of "the sustainable" as lodged in local knowledge, while rejecting development as a force that failed to affirm campesino culture and knowledge. CESA's critical posture vis-à-vis development was tolerated by donors while an external assessor reported that CESA was "excessively ideological."

At a reunion in Paucartambo, the mayor of the province spoke of CESA in glowing terms as an organization that was "developing" our backward and impoverished communities. The mayor seemed to miss the point completely and placed CESA's activities among a whole conglomerate of praiseworthy initiatives: to pave the Paucartambo-to-Cusco road; to promote the region's tourism (he spoke of a five-star hotel in Paucartambo); to turn bleak valleys into a flourishing greenery of crops and fruit trees; and to envisage and help construct the planned highway linking the Brazilian interior to Peru's Pacific coast, a trajectory that should place the small forgotten township happily in the midst of international trade.

It remains to consider the campesino response to agricultural development and to CESA. First, the claim could be advanced that campesinos were empowered by an institutional strategy such as CESA's that called upon campesino knowledge and the epistemic and ontic content of that knowledge. This would fit neatly within the counter-discursive space that CESA occupied, with development construed as a hegemonic discourse (Escobar 1995). However, the campesino farmers of the southern Peruvian Andes rarely adopted a counter-discourse. Their resistance to development was frequently expressed as a disapproving expression or a "turning away," a lack of interest, complacency, or an unwillingness to partake in projects in the way organizations expected of them.

Indeed, the task of the development anthropologist is often understood as one of mediating between development workers and campesinos in order to induce a greater level of participation in projects. As most development anthropologists appreciate, development projects can flounder for a myriad of reasons; it is too facile to hold that campesino resistance is rooted in a commitment to traditional knowledge and ontology. The resistance of project beneficiaries is certainly more complex than the way it is framed by development organizations who invoke the charge of peasant irrationality. In practice, campesinos not only reject technological interventions as much as they accept them. They also redefine them according to their own will, aspirations, knowledge, social organization, and the productive constraints of the ethnic economy (Shepherd 2004).

As CESA engaged the local communities, it was evident that many campesinos responded favorably to the institutional agenda. Moreover, it appeared that CESA's modus operandi gave way to less conflictual relationships with campesinos than did those of more standard agricultural NGOs. CESA did not typecast campesino communities according to their "level of development," and it desisted from the racial stereotyping of campesinos that proliferated in other development organizations. And given that CESA was not trying to transform local agriculture, resistance to the organization was both expressed differently and interpreted differently by CESA itself. Sometimes campesinos wished for inputs, interventions, or incentives that were clearly off-limits for CESA as these were too akin to the technological packages of Integrated Rural Development. The desires and needs of campesinos, however, presented a much more ambiguous picture than the parameters of discourse and counter-discourse would have us believe. There were no stable or unchanging alliances. Campesinos, too, fractured or disregarded the division between the internal and the external, between the traditional and the modern, between states of underdevelopment and development.

Whereas a developmentalist view of CESA was inclined to see CESA as evading the root causes of poverty and underdevelopment, in particular if those are to be equated with low productivity and the persistent use of traditional technologies, CESA emphasized the disruptions brought about by development and construed difficult local livelihoods as the historical effect of development, the market, and other interventions. Both views attempted to speak for campesinos, but neither was spoken by campesinos in such terms. Campesinos tended to stand aside from the discourse of development and underdevelopment and from the causal assertions embedded in that discourse. Their explanations were not framed within discursive packages, and explanation was rather transmitted through comment and gesture, embedded in actions, and situated in local experience. Agriculture, for them, was lived experience rather than packaged knowledge.

As scholars repeatedly assert, the peasantry is not a homogeneous entity. Even within the province of 
Paucartambo, a great amount of diversity exists among and between the campesino communities. These differences touch on socioeconomic distributions, on the degree to which social and agricultural change has taken effect over past decades, and on the proximity of markets, the existence of road access, and the level of institutional intervention from outside organizations. Within this context of heterogeneity, CESA instituted a very different politics to that of a standard development organization. First, CESA contributed to the making of a category called indigenous or local knowledge. Although that local knowledge certainly did (pre-) exist uncategorically in campesinos' experience, it was modified epistemologically by CESA, who drew it into a category that was dualistically objectified against Western or external knowledge. Curiously, some campesinos began to mirror to CESA's narratives, and that mirroring was in turn taken up in the form of campesino testimony to add weight to CESA's claims. In CESA's communities, I heard campesinos talk eloquently of their Andean knowledge in ways that I never encountered in other areas. It was also evident that CESA's approach was more appropriate where indigenous knowledge was already alive and well. To undo development where development had been performed with greater vigor might have invoked campesino resistance in much the same way as a standard NGO encountered greater resistance in its supposedly more "traditional" communities.

\section{Conclusion}

The desirability of development is seldom questioned, and local knowledge and technology are seldom considered as anything but obstacles to progress. For this reason, Andean peasants, like most other rural peoples of the Third World, are seen to be in need of development, of new technologies, technical know-how, and practices (Escobar 1995; Shepherd 2004). Although still in the minority, international and southern agricultural development organizations are increasingly turning their attention to the potential of local knowledge-it may be particular knowledge of the soils, of climate, of animals and plants, and of the types of practices as well as the social relations and worldview that accompany that knowledge. Thus a tension has emerged between, on the one hand, development interventions whose legitimacy stems from a perception of inherent weaknesses or inefficiencies in local productive modalities and, on the other, "development" that takes local knowledge as inherently or potentially valuable. It is precisely this latter image of "development" that im- plies a reconsideration of conventional development's strategies, and it is the tension between the two that inspires constructs of ethnodevelopment (or ethnoagricultural development), ecodevelopment, "alternative development," mutual learning, postdevelopment, and accompaniment, among others.

For many development organizations who err on the side of conventional agricultural development models associated with the technological style of the green revolution and the precepts of Integrated Rural Development, the very narratives they deploy to describe the pitfalls of local productive forms serve to prohibit a more balanced perspective of the possible strengths and weaknesses of local knowledge. In the day-to-day world of campesinos, there are many realities that cannot be fairly represented on a scale from traditional to modern, from persistence to change. I further suggest that such notions along with our few other ordering modes (poverty maps, literacy maps, agricultural assessments, productivity assessments, etc.) simplify rather than enrich our appreciations of the Andean farmers and their knowledge, that of both men and women. Conventional development organizations draw heavily on such simplifications. As a consequence they run the risk of pursuing strategies that are out of touch and dangerously incongruous with the cultural values and knowledge extant in the targeted communities.

Although development anthropologists are engaged in a broad spectrum of developmentalist initiatives, they are valued-and employed-precisely for their expert knowledge of the interrelationship between the world of development and that of those "being developed." They are called upon primarily to assist and harmonize that interrelationship. Often this implies a challenge to some of development's fundamental assumptions, and thus the job of the development anthropologist can be a tenuous one involving careful negotiation, juxtaposition, and reconciliation of differing viewpoints. Without assuming that indigenous knowledge is good simply because it is "indigenous," the development anthropologist must examine the possible value of local knowledge vis-à-vis development knowledge and seek points of intersection and reciprocity. This is precisely what CESA has done.

CESA's work rests on the categorization of an Andean knowledge system and sees that knowledge as a potential and innate resource rather than as an obstacle for development to transcend. CESA has done interesting work in bringing local knowledge into the purview of development and environmental conservation. Such a view mitigates the dominant penchant to dismiss the import of local knowledge. One of the 
more creative challenges for development anthropology is not only to seek to account for local culture and knowledge but also to find ways to incorporate the particular narratives and understandings of local people into development strategies. As revealed through CESA, these narratives are intrinsic to particular, and disparate, ways of organizing knowledge (epistemology) and being in the world (ontology). I offer CESA's example not as a blueprint for development anthropology but as an encouragement for them to think about local knowledge and not only explore the way it is excluded by the dominant development wisdom but also find novel ways of drawing local knowledge and development together such that development can proceed in ways more sympathetic to local knowledge.

Development anthropologists are well placed to identify peculiarly local livelihoods and understandings of the world, to appreciate the complexity of social life and intercultural interaction, and to aim for fairer knowledge-power relations. This is what I have wanted to show in CESA: it has creatively shaped its projects to attempt shared knowledge relations, such that "power over" (epistemic warrant) has strained toward "power with" (epistemic/ontic negotiation). While I would not claim that CESA represents the essential voice of the indigenous highlanders, it speaks to them in ways that are more approximate to their lived experience and lived knowledge than do its more developmentalist counterparts.

By refusing to adopt a priori the position that local knowledge is necessarily regressive and constitutes part of the problem of poverty, low productivity, and so on, development anthropologists shoulder the responsibility of translating development knowledge into terms that agree with the particular cultural values and knowledge of the targeted communities. These issues are especially pertinent to regions such as the Andes where there remains a strong and readily identifiable stock of local knowledge. In reconsidering the role of culture and cultural knowledge, one of the critical questions to ask is to what extent development's enduring economic assumptions and expertisebased methods restrict and constrain alternative forms of development that genuinely value local knowledge and other ways of being in the world different from our own.

\section{Acknowledgments}

I am most thankful to Luis Revilla as well as to all staff of Centro de Servicios Agropecuarios (CESA) for their friendship and their support of the research undertaken. I also thank Warwick Anderson, Martin Scurrah, Enrique Urbano, and Leanne Reinke for their valuable comments on earlier drafts.

\section{Notes}

1. Ayni is reciprocity, or the nonsimultaneous exchange of labor, seed, coca, and so forth that bond Andean peoples together.

2. Loma and q'ata refer to two agro-ecological levels. The former denotes the upper reaches of the mountainside, the latter the intermediate zone. These terms are made to equate to altitudinal figures. The quantified representations of meters above sea level, however, are rarely meaningful to peasants. As Ploeg (1993) observes, the peasant experience of altitude is flexibly interpretive: the terms up (arriba) and down (abajo) are linked to a complex nexus of interpretations that specify agricultural conditions, yet that appear inaccurate when taken solely as indications of relative altitude in the quantifiable (scientific) sense.

3. In Spanish refrescar la semilla means to cultivate a generation of seed at high altitude in order to revitalize it and free it of pathogens, thus ensuring that the seed retains its good quality.

4. The Quechua chuki (labranza cero in Spanish) is just one of numerous forms of tillage.

\section{References Cited}

Allen, Catherine J.

1988 The Hold Life Has: Coca and Cultural Identity in an Andean Community. London: Macmillan.

Altieri, Miguel A.

1995 Agroecology: The Science of Sustainable Agriculture. Boulder, CO: Westview Press.

Anderson, Anthony B., ed.

1990 Alternatives to Deforestation: Steps Toward Sustainable Use of the Amazon Rain Forest. New York: Columbia University Press.

Apffel-Marglin, Frédérique

1994 Development or Decolonization in the Andes? Cultural Survival Quarterly Winter:3-17.

1998 Introduction: Knowledge and Life Revisited. In The Spirit of Regeneration: Andean Culture Confronts Western Notions of Development. F. Apffel-Marglin, ed. Pp. 1-50. London: Zed Books.

Boulding, E.

1989 Cultural Perspectives on Development: The Relevance of Sociology and Anthropology. Alternatives XIV:107-122.

Browder, John O., ed.

1989 Fragile Lands of Latin America: Strategies for Sustainable Development. Boulder, CO: Westview Press. 
Dueñas, A., R. Mendivil, G. Lovaton, and A. Loaiza

1992 Campesinos y Papas: A propósito de la variabilidad y erosión genética en comunidades campesinas del Cusco. El Problema Agraria en Debate. SEPIA V:287-309.

Escobar, Arturo

1995 Encountering Development: The Making and Unmaking of the Third World. Princeton, NJ: Princeton University Press.

Gelles, Paul H.

2000 Water and Power in Highland Peru: The Cultural Politics of Irrigation and Development. New Brunswick, NJ: Rutgers University Press.

Golte, Jürgen

1980 La Racionalidad de la Organización Andina. Lima: Instituto de Estudios Peruanos

Grillo, R. D., and R. L. Stirrat, eds.

1997 Discourses of Development: Anthropological Perspectives. New York: Berg.

Gupta, Akhil, and James Ferguson, eds.

1997 Culture, Power, Place: Explorations in Critical Anthropology. Durham, NC: Duke University Press.

Hobart, Mark, ed.

1993 An Anthropological Critique of Development: The Growth of Ignorance. London: Routledge.

Latour, Bruno

1993 We Have Never Been Modern. Cambridge, MA: Harvard University Press.

Mayer, E., and M. Glave

1992 Papas Regaladas y Papas Regalo: Rentabilidad, Costos e Inversión. Perú: El Problema Agrario en Debate. SEPIA IV:87-120.

Morlon, Piere, Benjamín Orlove, and Alberic Hibon, eds.

1992 Tecnologías Agrícolas Tradicionales en los Andes Centrales: Perspectivas para el desarrollo. Lima: COFIDE-Proyecto Regional de Patrimonio Cultural.

Murra, John

1972 Formaciones Económicas y Politícas del Mundo Andino. Lima, Perú: Instituto de Estudios Peruanos.

Pérez Baca, Luis

1996 Crianza de Papas en Paucartambo-Qosqo. Cusco Perú: Centro de Servicios Agropecuarios.

Ploeg, J. D. v. d.

1993 Potatoes and Knowledge. In An Anthropological Critique of Development: The Growth of Ignorance. M. Hobart, ed. Pp. 209-228. London: Routledge.
Rengifo, Grimaldo, and Jorge Ishizawa

1997 Los Caminos Andinos de las Semillas. In Los Caminos Andinos de las Semillas. Pp. 1-43. Lima: Proyecto Andino de Tecnologías Campesinas.

Revilla Santa Cruz, Luis

1997 El Desarrollo y la Interculturalidad en la Experiencia del Centro de Servicios Agropecuarios,. Unpublished report. Cusco, Perú: CESA.

Shepherd, Chris J.

2004 Agricultural Hybridity and the Pathology of Traditional Ways: The Translation of Desire and Need in Postcolonial Development. Journal of Latin American Anthropology 9(2):235-266.

Shiva, Vandana

1991 The Violence of the Green Revolution: Third World Agriculture, Ecology, and Politics. London: Zed Books.

Turnbull, David

2000 Masons, Tricksters, and Cartographers: Comparative Studies in the Sociology of Scientific Knowledge. Sydney, Australia: Harwood Academic Press.

Van Cooten, D. E.

2001 Ethnoagricultural Development: Building on the Strengths of Indigenous Beliefs and Practices. Sanderson, NT: Kingdom Kookas Publishing.

Verran, Helen, and David Turnbull

1995 Science and Other Indigenous Knowledge Systems. In Handbook of Science and Technology Studies. S. Jasanoff, G. Markle, J. Peterson, and T. Pinch, eds. Pp. 115-142. London: Sage Publications.

Warren, Dennis M.

1996a Indigenous Knowledge Systems for Sustainable Agriculture in Africa. In Sustainable Development in Third World Countries: Applied and Theoretical Perspectives. V. U. James, ed. Pp. 15-24. Westport: Praeger.

1996b Indigenous Knowledge, Biodiversity Conservation, and Development. In Sustainable Development in Third World Countries: Applied and Theoretical Perspectives. V. U. James, ed. Pp. 81-88. Westport: Praeger.

Wynne, Brian

1996 May the Sheep Safely Graze? A Reflexive View of the Expert-Lay Divide. In Risk, Environment and Modernity: Towards a New Ecology. S. Lash, B. Szerszynski, and B. Wynne, eds. Pp. 66-83. London: Sage Publications.

Zimmerer, Karl S.

1996 Changing Fortunes: Biodiversity and Peasant Livelihood in the Peruvian Andes. Berkeley: University of California Press. 